\title{
Distribuição de sementes de milho e soja em função da velocidade e densidade de semeadura
}

\author{
Distribution of corn and soybean seeds in function of the sowing speed and density \\ Vilnei de Oliveira Dias ${ }^{\mathrm{I}}$ Airton dos Santos Alonço ${ }^{\mathrm{I}}$ Ulisses Benedetti Baumhardt ${ }^{\mathrm{I}}$ \\ Gustavo José Bonotto ${ }^{\mathrm{I}}$
}

\section{RESUMO}

Com o objetivo de avaliar a distribuição de sementes de milho e soja por uma semeadora-adubadora de precisão em função da velocidade de trabalho e da densidade de sementes, foi conduzido um experimento em pista de areia conforme norma internacional. Os tratamentos constaram da combinação entre quatro velocidades, três densidades de semeadura para o milho e quatro para a soja, sendo avaliadas a distribuição transversal, a distribuição longitudinal e a densidade final de sementes. Foi observado que as elevações da velocidade de trabalho de 3,5 para $7,0 \mathrm{~km} \mathrm{~h}^{-1}$, para milho, e de 4,3 para $11,0 \mathrm{~km} h^{-1}$, para soja, não reduziram significativamente as densidades finais de semeadura. $O$ aumento na densidade de semeadura de três para sete sementes $m^{-1}$, para milho, e de oito para 20, para soja, reduziu o percentual de espaçamentos aceitáveis para ambas as culturas, independentemente da velocidade de trabalho.

Palavras-chave: semeadora-adubadora, ensaio de desempenho, população de plantas.

\section{ABSTRACT}

With the objective to evaluate the distribution of corn and soybean seeds by a precision seeder in function of the displacement speed and seeds density, an experiment was made in track of sand according to international standard. The treatments consisted of the combination among four speeds, three sowing densities for the corn and four for the soybean, being appraised the transversal distribution, longitudinal distribution and final seeds density. It was observed that the elevations of the displacement speed from 3.5 to $7.0 \mathrm{~km} \mathrm{~h}^{-1}$ for the corn and from 4.3 to $11.0 \mathrm{~km} \mathrm{~h}^{-1}$ for the soybean did not reduce significantly the final densities of sowing. The increase in the sowing density from 3 to 7 seeds $\mathrm{m}^{-1}$ for the corn and from 8 to 20 for the soybean reduced the percentile of acceptable spacing's for both the cultures, independent of the displacement speed.

Key words: seeder-fertilizer, evaluation test, plant population.

\section{INTRODUÇÃO}

As culturas anuais do milho e soja estão entre as de maior relevância econômica da agricultura brasileira. Somando-se a produção das duas culturas na última safra, foram produzidas, no Brasil, cerca de 100 milhões de toneladas de milho e soja (IBGE, 2008).

A variabilidade de espaçamentos entre plantas é causa de redução na produtividade de culturas agrícolas (NIELSEN, 1995; MEROTTO JUNIOR et al., 1999). Elevar a densidade de plantas tem sido uma forma de potencializar a produtividade de grãos de soja (KUSS et al., 2008) e milho (ALMEIDA et al., 2000; SANGÓI et al., 2002). A elevação da produtividade das culturas devido ao melhor arranjo de plantas está associada ao aumento da radiação solar interceptada (ANDRADE et al., 2002). Sendo assim, para que sejam obtidas diferentes densidades de semeadura e, por conseguinte, populações de plantas, são necessárias variações na regulagem da semeadoraadubadora, o que pode interferir na qualidade da dosagem de sementes, expressa na distribuição de espaçamentos aceitáveis, múltiplos e falhos. A elevação da capacidade operacional propiciada pelo uso de velocidades de trabalho mais elevadas pode comprometer a qualidade da semeadura (LIU et al., 2004; CANOVA et al., 2007). Entretanto, KLEIN et al. (2002) afirmam que maiores velocidades de semeadura, como $10,7 \mathrm{~km} \mathrm{~h}^{-1}$, não afetam a distribuição de plantas de soja. MELLO et al. (2007), estudando as velocidades de 5,4; 6,8 e 9,8 $\mathrm{km} \mathrm{h}^{-1}$ na semeadura do milho com discos

IDepartamento de Engenharia Rural, Centro de Ciências Rurais (CCR), Universidade Federal de Santa Maria (UFSM), Av. Roraima, n 1000, 97105-900, Santa Maria, RS, Brasil. E-mail: vilnei@ymail.com. *Autor para correspondência. 
alveolados horizontais, verificaram que o aumento da velocidade reduziu a percentagem de espaçamentos normais entre as sementes, independentemente do híbrido. Logo, estudar a possível interação entre densidade de semeadura e velocidade de trabalho é de relevante importância na avaliação da qualidade do trabalho realizado por semeadoras-adubadoras. O objetivo deste trabalho foi avaliar o efeito da densidade e velocidade de semeadura das culturas do milho e soja na distribuição de sementes por uma semeadoraadubadora de precisão.

\section{MATERIAL E MÉTODOS}

O experimento foi desenvolvido em pista de areia, conforme a norma internacional UNE 68-081-88, equivalente à ISO 7256/1 (AENOR, 1988). Como preparo inicial da pista, foram realizadas duas gradagens pesadas com grade niveladora de arrasto. Para complementar o preparo e a correção final do microrrelevo da pista, efetuou-se nivelamento por meio de ancinhos e remoção de pedriscos e restos vegetais presentes na área. Os resultados da análise textural do solo da pista de avaliação revelaram que esta era composta por $77 \%$ de areia e $23 \%$ de argila, com granulometria de média a grossa. Esses valores estão em acordo com o ensaio no $n^{\circ}$.1.3 da norma UNE 68-08188.

Foi utilizada, no experimento, uma semeadora-adubadora de precisão para plantio direto com nove linhas espaçadas em $0,45 \mathrm{~m}$, chassi monobloco, com sulcadores tipo disco duplo defasado, rodas compactadoras em "v" e rodas limitadoras de profundidade lisas de borracha. Os dosadores de sementes eram do tipo disco alveolado horizontal, sendo de polietileno com 90 alvéolos de $7 \mathrm{~mm}$ de diâmetro, para soja, e 33 alvéolos de 11mm de diâmetro, para milho, com espessura de $7 \mathrm{~mm}$ e anel metálico de $3 \mathrm{~mm}$. Foram utilizadas sementes de milho híbrido Dekalb C435 com diâmetro de $10 \pm 0,8 \mathrm{~mm}$ e cultivar de soja 'BRS 247’, com diâmetro de 6,03 $\pm 0,31 \mathrm{~mm}$, sem tratamento fitossanitário ou grafite. Para tracionar a semeadoraadubadora, foi utilizado um trator agrícola com tração dianteira auxiliar (TDA), com $81 \mathrm{~kW}$ de potência na rotação nominal do motor. A TDA do trator permaneceu acionada durante todas as avaliações.

Os tratamentos constaram da combinação de densidades de sementes e velocidades de trabalho. Para a cultura do milho, foram testadas as densidades de três, cinco e sete sementes $\mathrm{m}^{-1}$ e velocidades de 3,5 , 4,3, 5,5 e 7,0 $\mathrm{km} \mathrm{h}^{-1}$. Para a cultura da soja, as densidades foram oito, 12, 16 e 20 sementes $\mathrm{m}^{-1}$ e as velocidades 4,3, 5,5, 7,0 e $11 \mathrm{~km} \mathrm{~h}^{-1}$. As velocidades foram obtidas pelo tempo gasto para percorrer uma distância entre dois pontos $(20 \mathrm{~m})$ do conjunto trator/semeadoraadubadora, sendo essa medida tomada cinco vezes. Como variáveis-resposta, foram avaliadas a regularidade de distribuição transversal (desvio médio) e longitudinal de sementes (percentual de aceitáveis, múltiplos e falhos) e a densidade média de semeadura. Para avaliar a regularidade de distribuição longitudinal de sementes, percorreu-se sobre a pista distância suficiente para a coleta de 150 espaçamentos entre sementes em quatro linhas ao acaso, na semeadora-adubadora. A altura dos mecanismos sulcadores foi regulada para que estes apenas tocassem o solo, depositando, dessa forma, as sementes na superfície arenosa da pista de avaliação. Após a passagem da semeadora-adubadora, eram medidos e anotados os espaçamentos entre sementes, utilizando para isso trena de $30 \mathrm{~m}$, prancheta e caneta. Na trena, eram identificadas as posições das sementes, e o espaçamento entre duas sementes era obtido pela diferença de leitura entre duas sementes consecutivas. Foram considerados falhos os espaçamentos com valor =1,5 Xref (teórico), múltiplos os espaçamentos =0,5 Xref e os demais foram classificados como aceitáveis (KURACHI et al., 1989; KACHMAN \& SMITH, 1995; COELHO, 1996). Para avaliar a uniformidade de distribuição transversal, foi contado o número de sementes em uma distância de $5 \mathrm{~m}$ após a passagem da semeadora-adubadora. De posse desses valores, foi calculada a densidade média semeada por cada linha e a densidade média da semeadora/adubadora. Para quantificar tal regularidade, foi utilizado o coeficiente denominado desvio médio descrito por COELHO (1996).

Os dados foram submetidos à análise de variância (ANOVA). Quando contrastes significativos foram encontrados, as variáveis desvio médio (sementes $\mathrm{m}^{-1}$ ) e percentual de espaçamentos aceitáveis, múltiplos e falhos em relação à velocidade de trabalho, foram ajustadas equações lineares ou polinomiais de segunda ordem. As médias da variável densidade final de semeadura (sementes $\mathrm{m}^{-1}$ ) foram comparadas pelo teste de Tukey, adotando-se 5\% de probabilidade de erro.

\section{RESULTADOS E DISCUSSÃO}

Na figura 1a, encontram-se os resultados da análise de regressões entre a regularidade de distribuição transversal de sementes de soja, expressa pelo desvio médio, e a velocidade de trabalho do conjunto trator/semeadora. Apenas para a densidade de 16 sementes $\mathrm{m}^{-1}$ a análise não foi significativa. $\mathrm{O}$ maior coeficiente de determinação foi obtido na densidade de 20 sementes $\mathrm{m}^{-1}$, seguida pelas

Ciência Rural, v.39, n.6, set, 2009. 

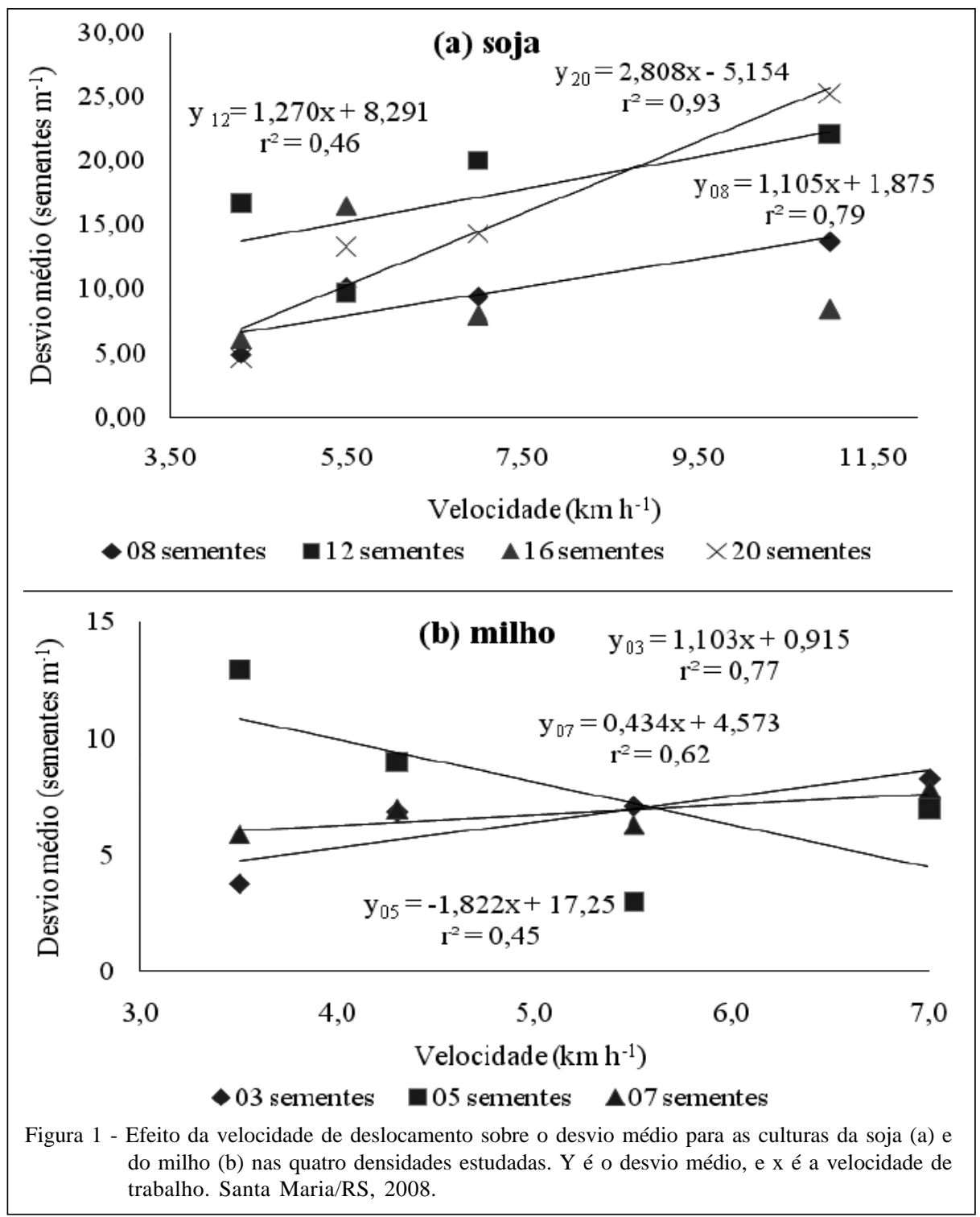

densidades de oito e 12 sementes $\mathrm{m}^{-1}$. As três regressões significativas indicam a elevação do desvio médio com o aumento da velocidade de trabalho independentemente da densidade de plantas testada. $\mathrm{O}$ coeficiente $\mathrm{b}$ da equação aplicada do tipo $\mathrm{y}=\mathrm{ax}+\mathrm{b}$ mostrou maior inclinação ascendente da reta na maior densidade de plantas (20 sementes $\mathrm{m}^{-1}$ ), seguido pela densidade de 12 sementes, que teve o coeficiente $b$ ligeiramente superior ao da equação que explica a relação da densidade de oito sementes $\mathrm{m}^{-1}$, mostrando maior influência da velocidade de trabalho na regularidade de distribuição de sementes em maiores densidades de plantas.

Na figura 1b, são mostrados os resultados da análise de regressões entre desvio médio e velocidade de trabalho para a cultura do milho. Embora todas as regressões tenham sido significativas, não se observou o mesmo comportamento para as três densidades testadas. Da mesma forma que, para a soja, as densidades de três e sete sementes $\mathrm{m}^{-1}$ apresentaram elevação no desvio médio com aumento da velocidade de semeadura. Entretanto, para a densidade de cinco sementes, o comportamento foi de redução do desvio médio, com coeficiente angular de módulo maior que para as duas outras densidades. $\mathrm{O}$ baixo valor de $\mathrm{r}^{2}$, na densidade de cinco sementes, é explicado por meio do ponto originado pela velocidade de $7,0 \mathrm{~km} \mathrm{~h}^{-1}$, onde ocorreu elevação do desvio médio.

Quanto à distribuição longitudinal de sementes de milho, para todas as velocidades e densidades testadas, houve redução no percentual de aceitáveis e aumento no número de falhos, com aumento da velocidade de trabalho (Figuras 2a, 2b e 2c). Essa 


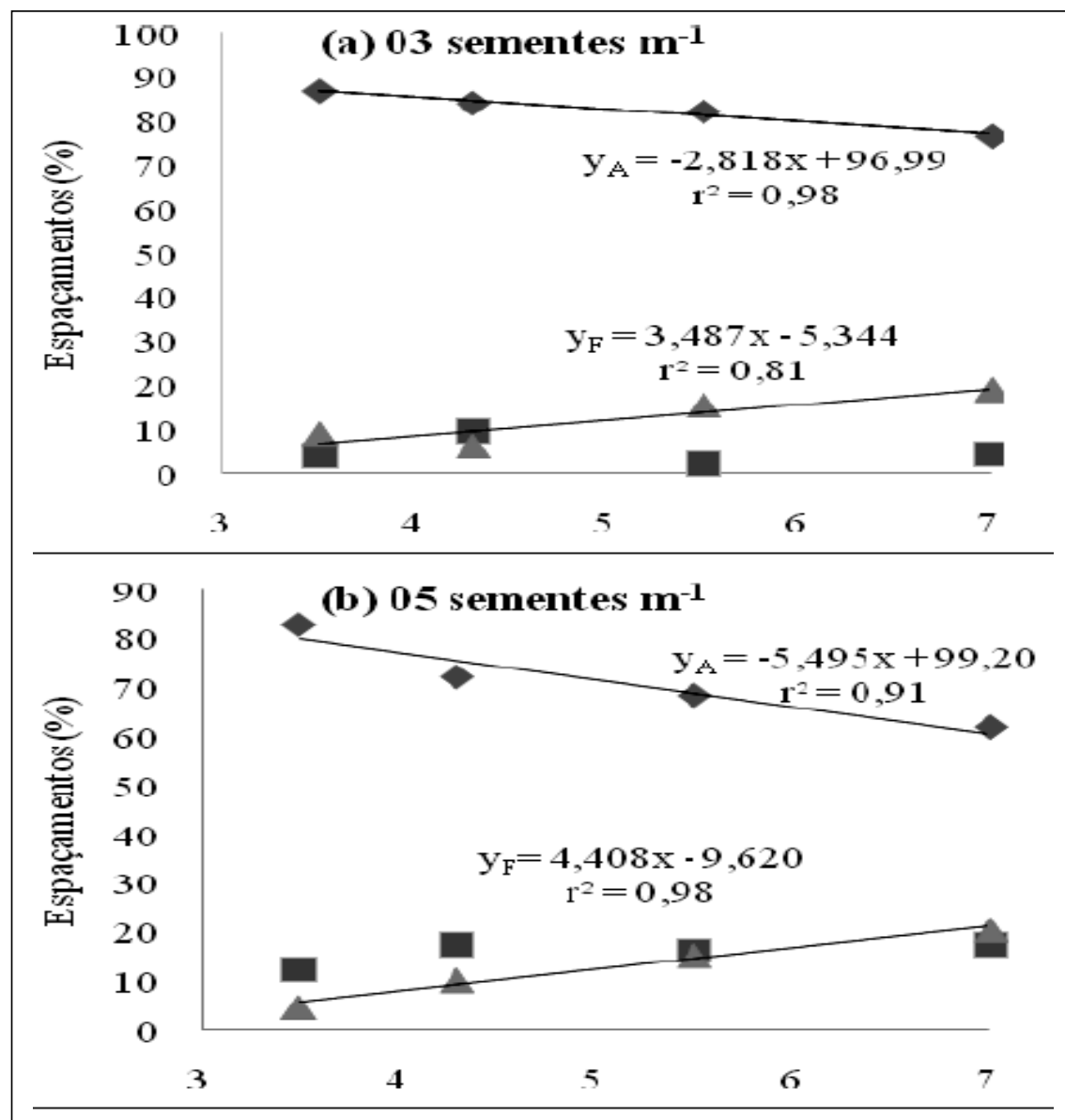

(c) 07 sementes $\mathbf{m}^{-1}$

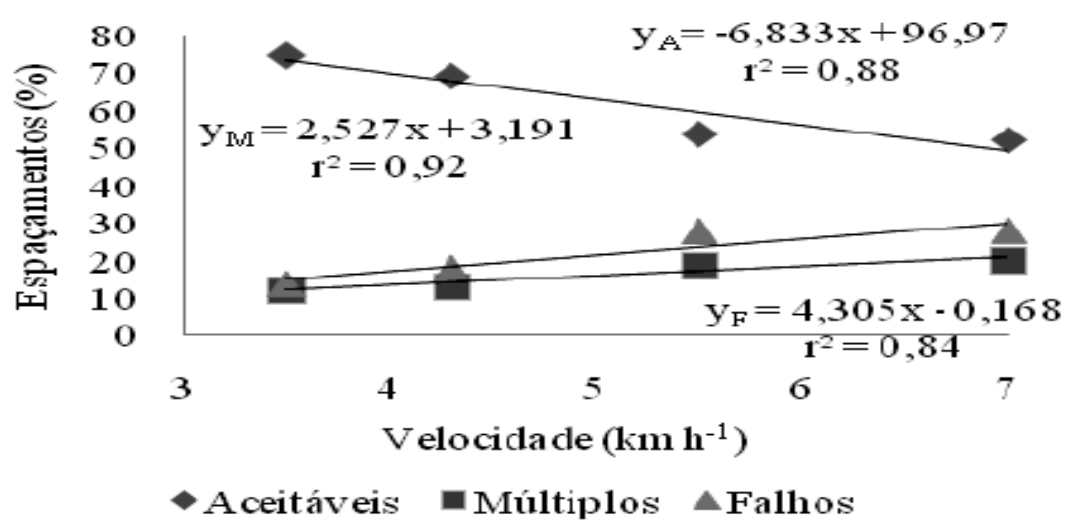

Figura 2 - Distribuição de espaçamentos aceitáveis, múltiplos e falhos obtidos para a cultura do milho em função da velocidade de deslocamento nas três densidades de sementes. $\mathrm{Y}$ é percentual de espaçamentos, e x é a velocidade de deslocamento. Santa Maria/ RS, 2008.

informação é corroborada por diversos autores (MELLO et al., 2003; LIU et al., 2004; MAHL et al., 2004), os quais verificaram efeito negativo do aumento da velocidade de trabalho na distribuição de sementes de milho, expresso pela redução do percentual de aceitáveis. O percentual de espaçamentos múltiplos teve aumento significativo apenas na densidade de sete sementes $\mathrm{m}^{-1}$.

Ciência Rural, v.39, n.6, set, 2009. 
$\mathrm{Na}$ cultura da soja, as regressões para espaçamentos aceitáveis foram significativas nas densidades de oito, 12 e 20 sementes $\mathrm{m}^{-1}$. Nas densidades de oito e 20 sementes, o melhor ajuste ocorreu por equações do tipo $\mathrm{y}=\mathrm{ax}^{2}+\mathrm{bx}+\mathrm{c}$ (Figuras 3a e 3d). Nesses casos, houve elevação dos aceitáveis até a velocidade de $7,0 \mathrm{~km} \mathrm{~h}^{-1}$, com redução na velocidade de $11,0 \mathrm{~km} \mathrm{~h}^{-1}$. Essa velocidade foi testada para simular condições extremas de semeadura, sendo impraticável em condições normais de solo e máquina. Entretanto, o objetivo da simulação foi alcançado, visto que, mesmo para a densidade de 12 sementes $\mathrm{m}^{-1}$, em que a regressão foi do tipo $\mathrm{y}=\mathrm{ax}+\mathrm{b}$, o número de aceitáveis foi menor na maior velocidade. Para as densidades de 12 e 16 sementes (Figuras 3b e 3c), houve elevação significativa do número de múltiplos com aumento da velocidade, fato não verificado na cultura do milho. Para a densidade de 20 sementes $\mathrm{m}^{-1}$, na medida em que houve aumento no percentual de aceitáveis, houve redução no percentual de espaçamentos múltiplos, e as inflexões das parábolas ocorrem na velocidade de 7,0 $\mathrm{km} \mathrm{h}^{-1}$. Esses resultados contrastam os resultados encontrados por KLEIN et al. (2002), os quais não verificaram efeito da velocidade de trabalho no percentual de múltiplos e falhos para soja, ao estudarem velocidades de 3,6 à $10,7 \mathrm{~km} \mathrm{~h}^{-1}$. Porém, a definição de aceitáveis empregada pelos autores, foi a média \pm o desvio padrão, o que pode ter interferido na interpretação dos dados.

Na figura 4, são mostradas as análises de regressões entre espaçamentos aceitáveis (\%) e densidade de semeadura (plantas $\mathrm{m}^{-1}$ ) para as duas culturas (4a: milho, 4b: soja). Tais equações foram obtidas tomando como variável dependente os dados de espaçamentos aceitáveis para todas as velocidades testadas, visto que o objetivo foi isolar a variável independente densidade de plantas. Foi observada redução no percentual de espaçamentos aceitáveis de

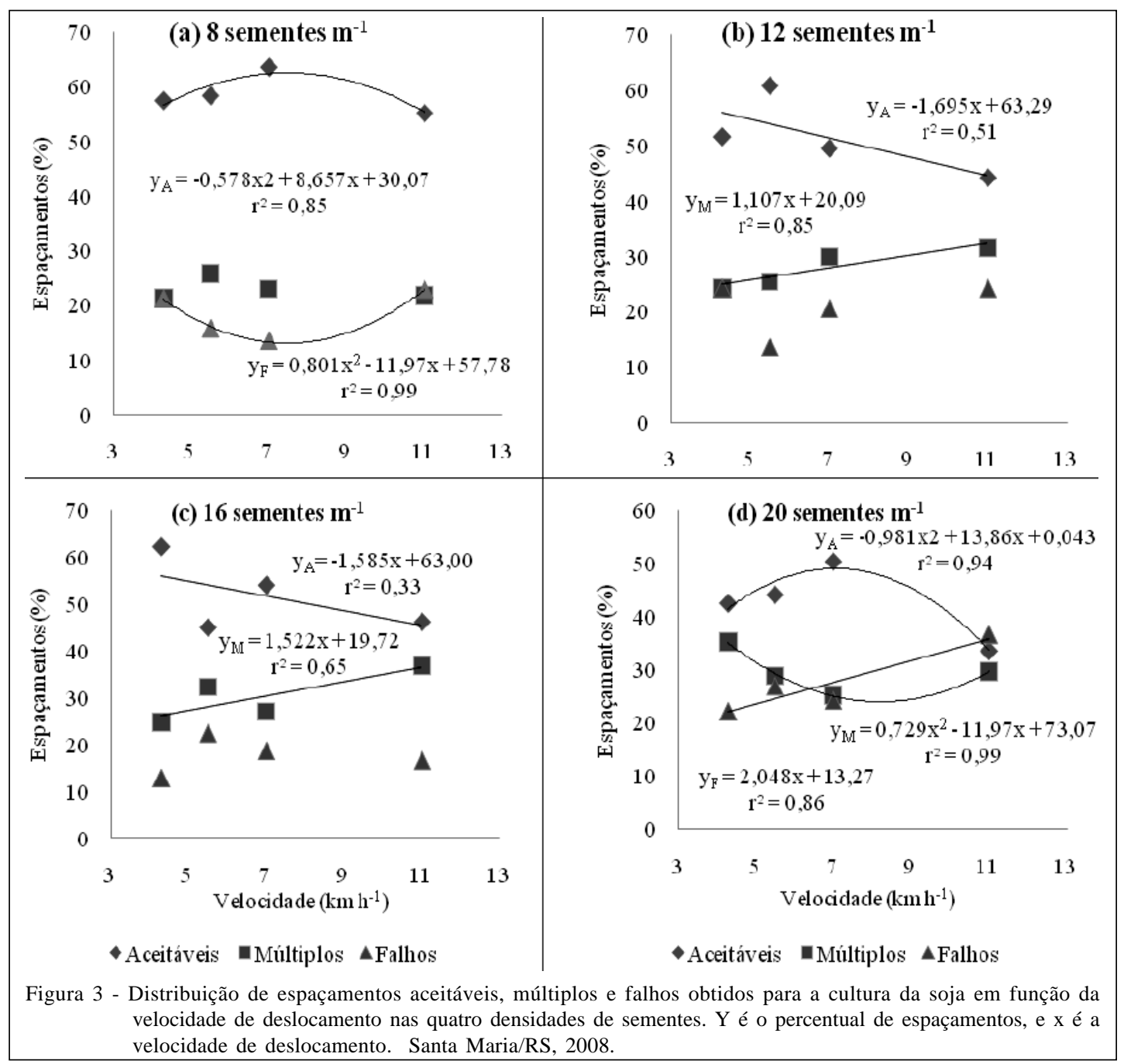

Ciência Rural, v.39, n.6, set, 2009. 


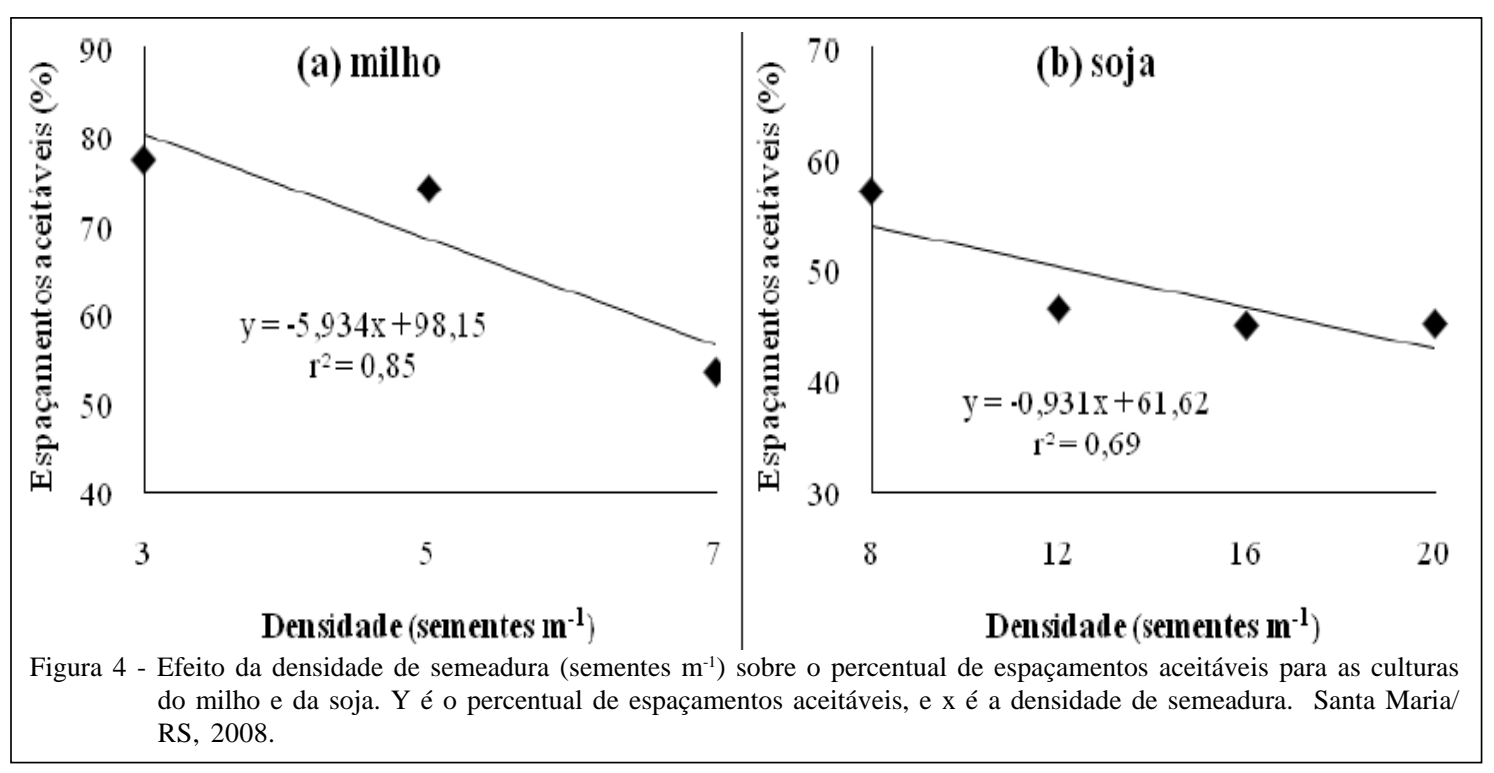

milho (Figura 4a) e soja (Figura 4b), com o aumento da densidade de semeadura. Esses resultados mostram que a redução do espaçamento entre sementes ocasionada pelo aumento da densidade provoca perda na qualidade de distribuição do mecanismo dosador tipo disco alveolado horizontal. Como o aumento da densidade foi obtido por alteração da relação de transmissão entre a roda motriz e o mecanismo dosador, essa maior densidade foi obtida por elevação da velocidade tangencial do disco alveolado. Para a cultura do milho, em que a distribuição de plantas no espaço é de fundamental importância para potencializar a produtividade da cultura (ANDRADE et al., 2002), a queda no percentual de aceitáveis com elevação da densidade foi maior que para a soja. Uma simples análise permite entender esse fato; de acordo com o conceito de aceitável, em que 0,5 Xref < aceitável < 1,5 Xref, o intervalo de tolerância que, para a densidade de três sementes $\mathrm{m}^{-1}$, foi de $333 \mathrm{~mm}$ se reduz para $143 \mathrm{~mm}$, ou seja, ocorre uma redução de $43 \%$ no limiar de indulgência. O disco utilizado para a cultura do milho, com 33 furos, na menor densidade, tinha uma revolução completa a cada $11 \mathrm{~m}$ e, na densidade de sete sementes $\mathrm{m}^{-1}$, esse espaço caiu para $4,7 \mathrm{~m}$, devido à maior velocidade tangencial deste. MOODY et al. (2003) encontraram resultados semelhantes para a cultura do algodão semeado com esse mesmo mecanismo dosador. Tais efeitos foram menos significativos para a soja, fato demonstrado pelo menor coeficiente angular da equação da reta.

Não houve redução significativa na densidade de semeadura com aumento da velocidade para as duas culturas (Tabela 1). Possivelmente, a alteração no número de aceitáveis descrita acima é compensada pela elevação no número de múltiplos, não alterando a densidade semeada, mas sim a distribuição das sementes na linha de plantio. Tais resultados contrastam os resultados obtidos por WEIRICH NETO et al. (2001), os quais estudaram a distribuição de sementes de feijão por disco alveolado horizontal e concluíram que, com o aumento da velocidade, houve decréscimo do índice de enchimento do mecanismo dosador de sementes, exceto para as sementes classificadas dimensionalmente como grandes, que apresentaram o índice de enchimento próximo do esperado em todas as velocidades estudadas. Os resultados deste trabalho, quanto à população de plantas, contrastam os resultados apresentados por MELLO et al. (2003), que não encontraram diferenças significativas na população de plantas de milho semeado com discos alveolados em função de velocidades variando de 3,5 a 7,7 $\mathrm{km} \mathrm{h}^{-1}$.

\section{CONCLUSÕES}

A elevação da velocidade de trabalho de 3,5 para $7,0 \mathrm{~km} \mathrm{~h}^{-1}$ reduziu o percentual de espaçamentos aceitáveis entre sementes para a cultura do milho, independentemente da densidade de plantas. O aumento na densidade de semeadura de 3três para sete sementes $\mathrm{m}^{-1}$, para milho, e de oito para 20, para soja, reduziu o percentual de espaçamentos aceitáveis para ambas as culturas, independentemente da velocidade de trabalho. O aumento da velocidade de deslocamento não reduziu significativamente a densidade de semeadura para ambas as culturas estudadas.

Ciência Rural, v.39, n.6, set, 2009. 
Tabela 1 - Relações entre velocidade de deslocamento e densidade de semeadura de milho e soja. Santa Maria/RS, 2008.

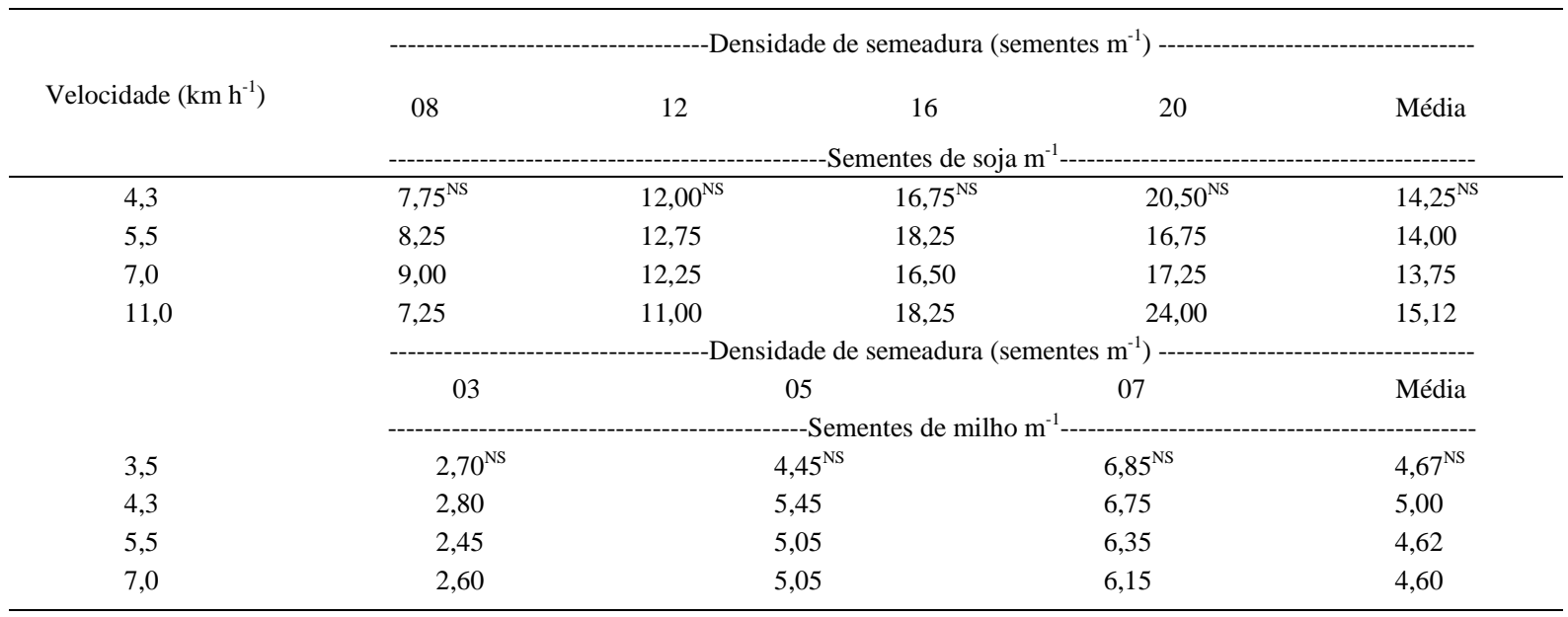

NS - não-significativo na coluna. CV soja: 18,30\%; CV milho: 8,90\%.

\section{REFERÊNCIAS}

AENOR. UNE 68-081-88 - Maquinaria para siembra sembradoras monograno: métodos de ensayo. Madrid, 1988. 18p.

ALMEIDA, M.L. et al. Incremento na densidade de plantas: uma alternativa para aumentar o rendimento de grãos de milho em regiões de curta estação estival de crescimento. Ciência Rural, v.30, n.1, p.23-29, 2000. Disponível em: <http://www.scielo.br/ s c i e l o.ph p ? s c ri p t = s c i_a r t t ex t \& pi d = S 010 3 - 84782000000100004\&lng=en\&nrm=iso\&tlng=pt $>$. Doi: $10.1590 /$ S0103-84782000000100004

ANDRADE, F.H. et al. Yield responses to narrow rows depend on increased radiation interception. Agronomy Journal, n.94, p.975-980, 2002.

CANOVA. R. et al. Distribuição de sementes por uma semeadoraadubadora em função de alterações mecanismo dosador e de diferentes velocidades de deslocamento. Engenharia na Agricultura, v.15, n.3, p.299-306, 2007.

COELHO, J.L.D. Ensaio e certificação de máquinas para a semeadura. In: MIALHE, L.G. Máquinas agrícolas: ensaio e certificação. Piracicaba: Fundação de Estudos Agrários "Luiz de Queiroz”, 1996. p.55-70.

IBGE. Levantamento sistemático da produção agrícola: junho de 2008. Disponível em: http://www.ibge.com.br/home/ estatistica/indicadores/agropecuaria/. On line. Acesso em: 14/7/ 2008 .

KACHMAN, S.D.; SMITH, J.A. Alternative measures of accuracy in plant spacing for planters using single seed metering. Transactions of the ASAE, v.38, n.2, p.379-387, 1995.

KLEIN, A. et al. Efeito da velocidade na semeadura direta da soja. Engenharia Agrícola, v.22, n.1, p.75-82, 2002.
KURACHI, S.A.H. et al. Avaliação tecnológica de semeadoras e/ou adubadoras: tratamento de dados de ensaios e regularidade de distribuição longitudinal de sementes. Bragantia, v.48, n.2, p.249-262, 1989. Disponível em: <http://www.scielo.br/s c i e l o . p h p ? s c ript = s c i _ a r t t ex t \& p i d = S 0006 $87051989000200011 \& \operatorname{lng}=$ en $\& n r m=$ iso\&tlng $=p t>$. Doi: 10.1590/S0006-87051989000200011.

KUSS, R.C.P. et al. Populações de plantas e estratégias de manejo de irrigação na cultura da soja. Ciência Rural, v.38, n.4, p.1133-1137, 2008. Disponível em: <http://www.scielo.br/ scielo.php? script =s ci_art text \& pid = S 0103 $84782008000400024 \& \operatorname{lng}=\mathrm{en} \& \mathrm{nrm}=\mathrm{iso} \& \operatorname{lng}=\mathrm{pt}>$. Doi: $10.1590 / \mathrm{S} 0103-84782008000400024$.

LIU, W. et al. Impact of planter type, planting speed, and tillage on stand uniformity and yield of corn. Agronomy Journal, n.96, p.1668-1672, 2004.

MAHL. D. et al. Demanda energética e eficiência da distribuição de sementes milho sob variação de velocidade e condição de solo. Engenharia Agrícola, v.24, n.1, p.150-157, 2004. Disponível em: <http://www.scielo.br/s c i e l o . p h p ? s c r i p $\mathrm{t}=\mathrm{s}$ c i a r t t e $\mathrm{x}$ t \& p i d $=\mathrm{S} \quad \begin{array}{lllll}0 & 1 & 0 & 0\end{array}$ 69162004000100017\&lng $=$ en \&nrm $=$ iso\&tlng $=p t>$. Doi: 10.1590/S0100-69162004000100017.

MELLO, A.J.R. et al. Produtividade de híbridos de milho em função da velocidade de semeadura. Engenharia Agrícola, Jaboticabal, v.27, n.2, p.479-486, 2007. Disponível em: <http://www.scielo.br/ scielo.php? script = s ci_art text \& pid=S 0100 $-69162007000300017 \& \operatorname{lng}=\mathrm{en} \& n r m=\mathrm{iso} \& \operatorname{lng}=\mathrm{pt}>$. Doi: $10.1590 /$ S0100-69162007000300017.

MELLO, L.M.M. et al. Distribuição de sementes e produtividade de grãos da cultura do milho em função da velocidade de semeadura e tipos de dosadores. Engenharia Agrícola, v.23, n.3, p.563-567, 2003.

MEROTTO JÚNIOR. A. et al. A desuniformidade de emergência reduz o rendimento de grãos de milho. Ciência Rural, v.29, n.4, p.595-601, 1999. Disponível em: <http://www.scielo.br/s cie lo.php? script=sci_arttext\&pid=S 010 
$3-84781999000400004 \& \operatorname{lng}=$ en $\& n r m=i s o \& t \operatorname{lng}=p t>$. Doi: 10.1590/S0103-84781999000400004.

MOODY, F.H. et al. Evaluating planter performance-cotton seed placement accuracy. Michigan: American Society of Agricultural Engineering, 2003. 13p. (ASAE Paper, 031146. 2003).

NIELSEN, R.L. Planting speed effects on stand establishment and grain yield of corn. Journal of Production Agriculture, n.8, p.391-393, 1995.
SANGÓI, L. et al. Bases morfofisiológicas para maior tolerância dos híbridos modernos de milho a altas densidades de plantas. Bragantia, v.61, n.2, p.101-110, 2002. Disponível em: <http:/ /www.scielo.br/scielo.php?script=sci_arttext\&pid=S0006$87052002000200003 \& \operatorname{lng}=$ en $\& n r m=i s o \& t \operatorname{lng}=p t>$. Doi: 10.1590/S0006-87052002000200003.

WEIRICH NETO, P.H. et al. Distribuição de sementes de feijão, classificadas dimensionalmente, utilizando mecanismo dosador tipo disco perfurado horizontal. Publicatio UEPG, v.7, n.1, p.7-20, 2001.

Ciência Rural, v.39, n.6, set, 2009. 